\title{
Unequal paternal contributions in black spruce polycross seedlots
}

\author{
D. L. ROGERS* \& T. J. B. BOYLE \\ Petawa National Forestry institute, Forestry Canada PO Box 2000, Chalk River, Ontario, Canada Kal iso
}

\begin{abstract}
Differences in male reproductive success in seven black spruce clones were assessed using isozyme analysis of seeds produced with polymix pollen. Four polycross seedlots were analysed and each showed significant departures from expected contributions by the participating males. Possible explanations for these differences are explored. Results are discussed in relation to the use of polycross seeds from controlled breeding efforts and seed orchards.
\end{abstract}

Keywords: black spruce, isozyme analysis, paternal contribution, polycross seeds.

\section{Introduction}

Seeds produced by controlled pollination with a mixture of pollen from more than one male parent (polycrosses) have a variety of uses in tree improvement programmes. They are frequently used as an elegant and economical system for evaluating general combining ability (GCA) in forest trees (Fowler, 1987) and agricultural crops (e.g. Aastveit \& Aastveit, 1990). Polycrosses are useful in producing genetically improved materials from assortative mating more simply and less expensively than single-pair matings or other controlled pollination designs. Polycrosses also provide an opportunity to assess differences in paternal contributions. Using the polycross, differential male reproductive success has been demonstrated for several forest tree species, including Pseudotsuga menziesii (Mir.) Franco (Apsit et al., 1989), Picea abies (Schoen \& Cheliak, 1987), and Pinus radiata (Moran \& Griffin, 1985). There is also some evidence for this phenomenon in Picea glauca (Schoen \& Stewart, 1986). As the pollinations in each case were controlled, differential reproductive success cannot be explained by differences in amount, timing or proximity of pollen source.

Differences in relative male reproductive success, under equal opportunity conditions for pollination, may be postulated to be the result of some kind of selection mechanism. Traditionally, studies of natural selection in forest tree species have focused attention on post-seed production stages. However, selection

*Present address: Department of Forestry and Resource Management, University of California, Berkeley, CA 94720, USA. could theoretically play an important role at prezygotic (compatibility) or post-zygotic (viability) stages. Selection at these stages could be due to environmental influences, female selection, male competitiveness, female-male interactions, or a combination. Although well documented in angiosperm species, relatively little is known about pre-zygotic selection mechanisms in gymnosperms. However, post-zygotic selection and detection is well known in the latter (Owens \& Blake, 1985).

The potential operation of selective advantage at pre-zygotic stages in forest tree species offers another insight into genetic variation and with it, perhaps, the opportunity for selection. In addition to providing basic information about reproductive biology, this type of study has implications for at least two areas of activity in applied forest genetics. First, the use of polycross-derived seed in estimation of genetic parameters (i.e. GCA) assumes equal reproductive success of all participating males. Failure of this assumption of equal male success leads to biased GCA estimates. Secondly, genetic diversity in seed orchard origin seeds would be affected, and probably depressed, by this departure from random mating represented by differences in male or gametic success. Also, the genetic quality of black spruce seed produced with polymix pollen is of particular interest in Ontario. Polycross families have been used in the production of rooted cuttings for forest regeneration in northern Ontario.

This paper presents results of a paternity analysis of several polycross seedlots of black spruce, Picea mariana [Mill.] B.S.P., one of Canada's most widely distributed and economically significant forest tree species. The purpose of the study is to provide a 
preliminary inquiry into the possibility of differential male reproductive success in this species, and to discuss the implications of the results.

\section{Materials and methods}

\section{Experimental material}

The eight black spruce clones involved in this study originally came from open-pollinated seed selected from natural stands by the Spruce Falls Power and Paper Company near Kapuskasing, Ontario. The seedlings were grown in a 'seed production area' and scions were taken from selected trees in 1973 by

Table 1 Pollen germination test results

\begin{tabular}{ll}
\hline Clone & Per cent germination* \\
\hline 2641 & 42 \\
2645 & 20 \\
2651 & 64 \\
2653 & 58 \\
2670 & 46 \\
2671 & 42 \\
2675 & 38 \\
\hline
\end{tabular}

*Based on a randomly selected field of 100 pollen grains.

Table 2 Single-pair mating scheme

\begin{tabular}{|c|c|c|c|c|}
\hline \multirow[b]{2}{*}{ Females } & \multicolumn{4}{|l|}{ Males } \\
\hline & 2653 & 2675 & 2651 & $2655^{*}$ \\
\hline 2641 & $\mathrm{X}$ & & & \\
\hline 2670 & & $X$ & & \\
\hline 2671 & & & $\mathrm{x}$ & \\
\hline 2645 & & & & $X$ \\
\hline
\end{tabular}

*Not used in the polycross study.
Canadian Forestry Service personnel. The scions (three to five per clone) were grafted onto white spruce understock and planted in row plots at the Petawawa National Forestry Institute in 1981. Based on the performance of open-pollinated families from these same ortets on seven sites in northern Ontario (Boyle, 1986), eight clones were identified for production of second-generation material. In May 1987, pollen was collected from seven of these clones. Microstrobili were collected just prior to natural dehiscence. Black spruce microstrobili are very sensitive and readily abort unless collected toward the extreme latter stages of development (Copis, 1990a). The pollen was extracted using techniques that have been developed to protect pollen viability and guard against contamination (Copis, 1990b). Pollen germination tests of each clone's pollen was carried out using a 5 per cent sucrose solution. Germination counts were made $24-48 \mathrm{~h}$ after pollen was introduced to the germination medium (Copis, 1990b) (Table 1).

Four single-pair matings, involving all eight clones, were performed according to the design in Table 2. Controlled pollinations with polymix pollen were conducted with four clones as females and 6-7 clones as males. For the polycross matings, pollens were mixed in equal volumes according to a scheme that excluded selfing (Table 3). Considerable care was taken to ensure similar conditions for all pollens in the polymixes, such as using fresh pollen and desiccating all pollen to the same moisture level prior to measuring equal volumes. One factor that was not controlled was the relative number of pollen grains per male in the polymixes. Because pollen volume was controlled and pollen size often varies greatly among parents ( $J$. Owens, personal communication) there could have been significant differences in the number of pollen grains per male.

Pollinations were completed in situ, bagging the megastrobili just as the buds were beginning to enlarge, and introducing the polymix pollen into the bag with a needle as the flowers matured to the receptive stage (Copis, 1990c). All crosses were completed within

Table 3 Breeding design for polycross families

\begin{tabular}{lllllllll}
\hline & & \multicolumn{3}{c}{ Males } & & & & \\
\cline { 3 - 8 } Seedlot \# & Females & 2641 & 2645 & 2651 & 2653 & 2670 & 2671 & 2675 \\
\hline 1 & 2653 & $\mathrm{X}$ & $\mathrm{X}$ & $\mathrm{X}$ & & $\mathrm{X}$ & $\mathrm{X}$ & $\mathrm{X}$ \\
2 & 2651 & $\mathrm{X}$ & $\mathrm{X}$ & & $\mathrm{X}$ & $\mathrm{X}$ & $\mathrm{X}$ & $\mathrm{X}$ \\
3 & 2670 & $\mathrm{X}$ & $\mathrm{X}$ & $\mathrm{X}$ & $\mathrm{X}$ & & $\mathrm{X}$ & $\mathrm{X}$ \\
4 & 2656 & $\mathrm{X}$ & $\mathrm{X}$ & $\mathrm{X}$ & $\mathrm{X}$ & $\mathrm{X}$ & $\mathrm{X}$ & $\mathrm{X}$ \\
\hline
\end{tabular}


several days. The cones were collected in September and the seed extracted in mid-November. All crosses produced in excess of 100 (filled) seed.

\section{Electrophoretic analysis}

Multi-locus genotypes of the males used in the polymixes were established by analysing 10 seeds from each of the single-pair matings. Seeds were germinated on moistened filter paper in a controlled environment with a daily cycle of $30^{\circ} \mathrm{C}$ for $8 \mathrm{~h}$ and $20^{\circ} \mathrm{C}$ for $16 \mathrm{~h}$. When the radicle emerged and extended beyond the seed coat by approximately $5 \mathrm{~mm}$, the seeds were dissected into the embryo and the megagametophyte. For each seed, tissue samples from these two sources were homogenized in a suitable extraction buffer and analysed in adjacent positions with starch gel electrophoresis, following the procedures of Cheliak \& Pitel (1984). The female genotype was determined by direct observation of the haploid megagametophytes, while the male genotype was inferred from embryo (diploid) and megagametophyte genotypes. In order to screen the isozyme variation among the seven clones used as male parents, 21 loci, representing 16 enzyme systems, were examined (i.e. Pc, Tpi, Me, Pgi, Aat, Lap, Aco, Pgm, Idh, 6Pgd, Ald, Pep, G6pd, Mdh, Fum, Skdh*). Variation was evident at seven loci implying that these loci were good subjects for the polycross analysis (Table 4). Genotypes of the seven males used in the polycross are presented in Table 5.

For three of the four polycross seedlots, 80 seeds were assayed; 72 were assayed for the fourth. Seven polymorphic loci (four diallelic and three triallelic),

*See, for example, Cheliak \& Pitel (1984) for abbreviation definitions. representing six enzyme systems, were scored. Pollen contributions were determined for each seed according. to the method described for the seeds from single-pair matings.

When the pollen contribution had been determined, paternity was assigned to each seed. As all male parents did not have unique 7-locus genotypes, assignment to a single male was not always possible. In particular, males \#2670 and \#2671 had identical genotypes. The number of possible pollen genotypes from any given parent is $2^{n}$, where $n=$ the number of heterozygous loci. Thus, although the seven male parents have a total of 94 possible gametic genotypes, some of these are common to two or three parents (Fig. 1). In the cases where a pollen contribution could have been made from two, or even three, males, partial and equal credit for that seed was awarded to the candidate males (Wiselogel \& van Buijtenen, 1988). This type of paternity assignment has been previously labelled as a 'simple exclusion technique' (Ellstrand, 1984; Hamrick \& Schnabel, 1985).

Table 5 Seven-locus genotypes of the seven black spruce males

\begin{tabular}{llllllll}
\hline Male & Pgi 1 & Pgm & G6pd & 6Pgd 1 & 6Pgd 2 & Mdh 3 & Skdh \\
\hline 2671 & FF & FS & FS & FS & SS & FF & FS \\
2651 & FS & FM & SS & SS & SS & FF & SS \\
2645 & FM & MS & SS & SS & SS & FM & FF \\
2670 & FF & FS & FS & FS & SS & FF & FS \\
2675 & FM & MS & FS & FS & FS & FF & SS \\
2641 & FF & FM & FS & SS & FS & FS & FF \\
2653 & FF & FF & SS & SS & SS & FM & SS \\
\hline
\end{tabular}

Table 4 Loci showing variation among the male parents

\begin{tabular}{|c|c|c|c|}
\hline Isozyme & Abbreviation & E.C.* & $\begin{array}{l}\text { No. of allozymes } \\
\text { observed }\end{array}$ \\
\hline $\begin{array}{l}\text { Glucose-6-phosphate } \\
\text { dehydrogenase }\end{array}$ & G6pd & 1.1 .1 .49 & 2 \\
\hline Malate dehydrogenase 3 & Mdh 3 & 1.1.1.37 & 3 \\
\hline Phosphoglucomutase & Pgm & 2.7.5.1 & 3 \\
\hline $\begin{array}{c}\text { 6-Phosphogluconate } \\
\text { dehydrogenase } 1\end{array}$ & $6 \mathrm{Pgd} 1$ & 1.1 .1 .44 & 2 \\
\hline $\begin{array}{c}\text { 6-Phosphogluconate } \\
\text { dehydrogenase } 2\end{array}$ & $6 \mathrm{Pgd} 2$ & 1.1 .1 .44 & 2 \\
\hline $\begin{array}{l}\text { Phosphoglucose } \\
\text { isomerase } 1\end{array}$ & Pgi 1 & 5.3 .1 .9 & 3 \\
\hline Shikimate dehydrogenase & Skdh & 1.1.1.25 & 2 \\
\hline
\end{tabular}

*Enzyme Commission designations. 


\section{Statistical analysis}

Tables were constructed for each seedlot displaying the number of successful pollinations by each male parent, either as the sole candidate or as a shared contributor with other possible male parents. Due to the exclusion of selfs from the breeding plan, there were three missing values in these tables. In preparation for analysis, average values, based on the other three seedlots, were substituted for the missing data and degrees of freedom adjusted accordingly. Following these fre-

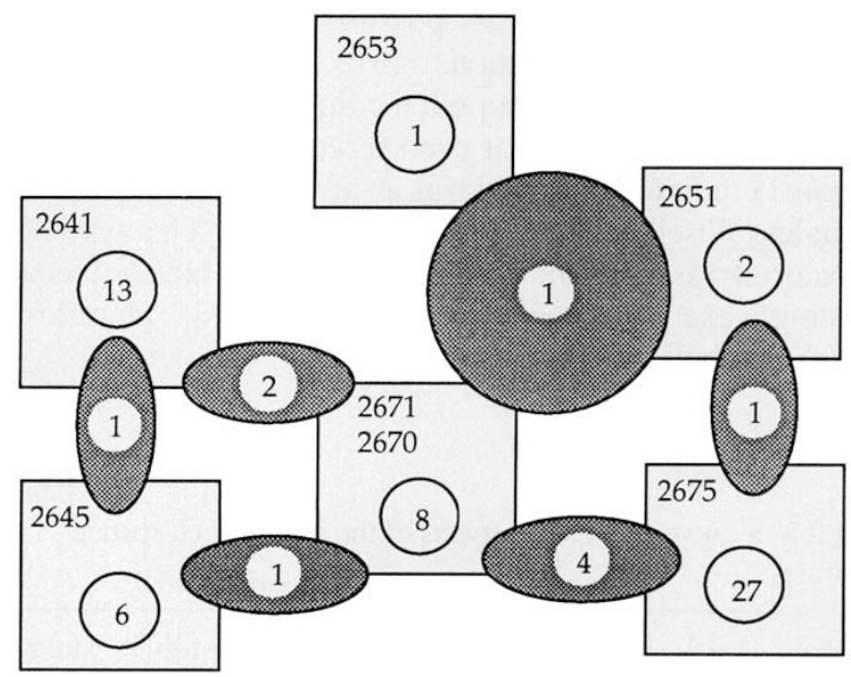

Fig. 1 Gametic genotypes for seven black spruce male parents. Numbers within circles are the number of gametic types unique to that parent. Numbers within shaded spaces show gametic types common to two or more parents. quency estimates, other male frequencies in each seedlot were adjusted to maintain both total seed number and their original relative frequency. The effect of using mean-based estimates was to dampen variation within and among seedlots, and increase the probability of Type II errors. As the selfing phenomenon was not of interest in this investigation, this statistical approach was preferable to using real data for these three values.

The four polycross seedlots were considered 'replicates' for log likelihood ratio tests (i.e. $G$-tests), which are more suitable for such additive goodness-offit tests than the traditional chi-square test (Sokal \& Rohlf, 1981). The $G$-test for heterogeneity $\left(G_{H}\right)$ was applied to test the hypothesis that the ratios of progeny sired by the different males were homogeneous among seedlots. A pooled $G$-test $\left(G_{\mathrm{p}}\right)$ was then used to determine the goodness-of-fit of the pooled observations to the expected. Finally, given the significant heterogeneity test, the total $G$ (i.e. $G_{\mathrm{T}}=G_{\mathrm{H}}+G_{\mathrm{P}}$ ) was partitioned into contributions due to the individual seedlots to determine whether some or all were significantly different from the expected values. The reference for all calculations is Sokal \& Rohlf (1981).

\section{Results}

The relative reproductive success of each male, by individual seedlot and collectively, is shown in Table 6 and Fig. 2, respectively. In general, males \#2641, 2645,2651 and 2653 have low numbers of progeny, while \#2670, 2671 and 2675 have sired relatively high proportions of the seed. The number of progeny

Table 6 Relative reproductive success for the seven black spruce males involved in the polycrosses*

\begin{tabular}{|c|c|c|c|c|c|c|c|c|}
\hline \multirow{2}{*}{$\begin{array}{l}\text { Seedlat } \\
\text { no. }\end{array}$} & \multicolumn{8}{|c|}{ Males } \\
\hline & 2641 & 2645 & 2651 & 2653 & 2670 & 2671 & 2675 & $N$ \\
\hline 1 & $\begin{array}{l}2.72 \\
(3)\end{array}$ & $\begin{array}{l}12.10 \\
\langle 12\rangle\end{array}$ & $\begin{array}{l}3.63 \\
(3)\end{array}$ & $\underline{7.4}$ & $\begin{array}{l}15.27 \\
(0)\end{array}$ & $\begin{array}{c}15.27 \\
(0)\end{array}$ & $\begin{array}{l}23.60 \\
(19)\end{array}$ & 80 \\
\hline 2 & $\begin{array}{l}4.25 \\
\text { (1) }\end{array}$ & $\begin{array}{l}5.83 \\
(4)\end{array}$ & 4.4 & ${ }_{(2)}^{3.15}$ & $\begin{array}{l}20.95 \\
(0)\end{array}$ & $\begin{array}{c}20.95 \\
(0)\end{array}$ & $\begin{array}{l}20.48 \\
(13)\end{array}$ & 80 \\
\hline 3 & $\begin{array}{l}3.65 \\
(3)\end{array}$ & $\begin{array}{l}11.22 \\
(10\rangle\end{array}$ & $\begin{array}{l}3.27 \\
(0)\end{array}$ & $\begin{array}{l}7.8 \mathrm{I} \\
(7)\end{array}$ & $\underline{17.55}$ & $\begin{array}{l}17.64 \\
(10)\end{array}$ & $\begin{array}{c}10.84 \\
(5)\end{array}$ & 72 \\
\hline 4 & $\begin{array}{l}13.00 \\
(10)\end{array}$ & $\begin{array}{l}7.67 \\
(5)\end{array}$ & $\begin{array}{l}4.50 \\
(4)^{2}\end{array}$ & $\begin{array}{r}0 \\
(0)\end{array}$ & $\begin{array}{l}14.67 \\
(0)\end{array}$ & $\begin{array}{c}14.67 \\
(0)\end{array}$ & $\begin{array}{l}25.50 \\
(22)\end{array}$ & 80 \\
\hline Total & 23.62 & 36.82 & 15.80 & 18.36 & 68.44 & 68.53 & 80.42 & 312 \\
\hline
\end{tabular}

*Estimated values in the table are underlined.

$N=$ the total number of seeds electrophoretically analysed.

Values in parentheses are numbers of seed uniquely attributable to that male. Note that for all seedlots except $\# 3$, males $\# 2670$ and $\# 2671$ are indistinguishable, hence their 0 values for undisputed progeny. 


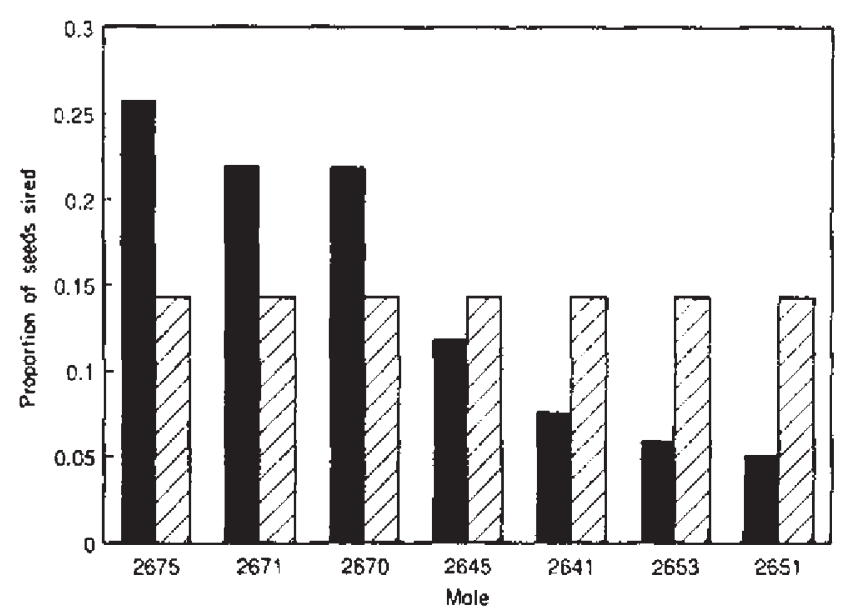

Fig. 2 Relative reproductive success among black spruce males. (1) Observed, (z) expected.

that are attributable to a single male ranges from 25 per cent (seedlot \#2) to 52 per cent (seedlot \#4). The remainder could be one of two or three males, due to common gametes among candidate male parents (Table 6). This low proportion of seed that can be linked to a unique male is largely due to the common genotypes of males \#2670 and 2671 , which are separable in only one seedlot (i.e. \#3). The presence of gametes indistinguishable for several males is not an uncommon situation for such analyses (e.g. Schoen \& Cheliak, 1987; Wiselogel \& van Buijtenen, 1988). Most progeny totals of these two parents were due to seed that could have come from either, but not any other, clone.

The pooled $G$-test shows that the combined data from all polycross seedlots deviate significantly from the expected situation of equal contributions by all males $\left(G_{\mathrm{P}}=103.4\right.$, Table 7). Partitioning the total $G$ test value into contributions by individual seedlots showed that, in every case, the ratios (of male reproductive success) observed were significantly different from those expected.

The test for heterogeneity among seedlots showed significant differences among families in ratios of progeny from each male parent $\left(G_{\mathrm{H}}=34.76\right.$, Table 7). for example, although there are over 20 seeds to the credit of male \#2675 for three of the polycross seedlots, in $\# 3$ this male is only credited with 11 seeds. Another notable example is male \# 2641 which, while having parented only 3-4 seed for three of the seedlots, has sired 13 seeds in seedlot \#4. These results indicate that male success is dependent upon the female genotype involved in the cross.

\section{Discussion}

The results of isozyme analysis provide evidence that black spruce males are not necessarily equally effective
Table 7 G-test summarył

\begin{tabular}{lccc}
\hline Tests & d.f. & $G$ \\
\hline Pooled & 6 & $103.04^{*}$ & \\
Heterogeneity & 15 & $34.76^{*}$ & \\
Total & 21 & $137.80^{*}$ & \\
\hline Seedlot no. & Female & d.f. & $G$ \\
\hline 1 & 2653 & 5 & $30.62^{*}$ \\
2 & 2651 & 5 & $41.98^{*}$ \\
3 & 2670 & 5 & $21.36^{*}$ \\
4 & 2656 & 6 & $43.84^{*}$ \\
Total & & 21 & $137.80^{*}$ \\
\hline
\end{tabular}

*Probability $\leq 0.01$ that $\chi^{2} \geq$ chi square.

†Degrees of freedom have been adjusted for parameter estimates.

in siring seed even when provided with apparently equal opportunity conditions. Certainly three of the males used in this study were more reproductively successful than the other four. This result in black spruce is consistent with that reported for several other forest tree species, as noted in the introduction. The sole exception to this trend at present appears to be Pinus taeda L., in which polycross study results supported the equal mating hypothesis (Wiselogel \& van Buijtenen, 1988). Lindgren \& Yazdani (1988) found little evidence of unequal contributions by (outcrossing) pollen in Pinus sylvestris (L.), but the study was inconclusive as only one seedlot with two participating males was analysed.

Let us first consider the simplest explanation for the study results. In this investigation, pollen volume and timing (i.e. phenology) were controlled, so these factors could not be responsible for substantial differences in male reproductive success. Pollen viability, although varying among males, was probably not markedly different given the likely confidence limits of the germination test. Further, if the polien viability diffetences among males were significant, then the opposite effect to that observed would have been expected. The two males with the lowest reproductive success (\# 2653 and 2651) actually had the highest pollen viability (Table 1 and Fig. 2).

It has already been mentioned that pollen size was not measured and differences among males are possible, but unknown. Also, specific rates of pollen germination and vigour of growth were not tested, and these could have influenced relative reproductive success (J. Owens, personal communication). However, if certain males had an advantage conferred by their pollen grain size or vigour, one would expect similar 
results in every seedlot. Yet there was significant heterogeneity among seedlots, suggesting some specificity in male-female interactions.

Given that the procedural or physical explanations seem inadequate to account for the marked differences in reproductive success in certain males, other plausible mechanisms could be explored. Certainly one possibility is male competition, such as differential pollen tube growth rates. The extent to which this operates in black spruce, and the genetic basis for these traits are not known. In Dianthus chinensis, Mulcahy \& Mulcahy (1975) showed that competition between pollen genotypes from a single plant can influence the quality of the $F_{1}$ generation.

Another cluster of possible explanations lies within the topic known as 'female choice'. As argued convincingly by Stephenson \& Bertin (1983), because the only benefit that the matemal sporophyte presumably derives from mating is genes, then if pollen availability is not limiting and pollen grains differ in genetic quality, "the maternal sporophyte is under selective pressure to allow only those pollen grains with the highest genetic quality to sire her crop". Recognition systems supporting the concept of female selection have been studied extensively in angiosperms, and "the few immunological studies that have been conducted [with gymnosperms] suggest that this may be a useful avenue of research in conifers" (Owens \& Blake, 1985). Although this may apply somewhat to spruce species, as this genus requires pollen for every ovule development, it may not apply to many conifers where pollen is of no consequence in ovule development (J. Owens, personal communication).

The putative selection mechanism could operate via post-fertilization embryo abortion. Black spruce exhibits archegonial polyembryony, characterized by independent fertilization of more than one archegonium within an ovule, giving rise to heterogenic embryos within the ovule. Although empirical evidence is lacking, polyembryony provides a mechanism by which selection among genetically distinct and perhaps variably vigorous embryos could occur, without wastage of ovules (Sorensen, 1982).

As black spruce most often grows in predominantly pure, contiguous stands, there is rarely a paucity of pollen (OMNR, 1988a). Hence, the first prerequisite for female selection is probably satisfied. Also, the tendency for black spruce to supplement its sexual reproduction with the vegetative mode of 'layering' seems to present additional likelihood for selfing in this species unless countered by some (pre- or post-zygotic) selection process(es). Although studies are scarce in gymnosperms, several studies with angiosperms indicate that genes are expressed in the pollen, allowing selection for differences. Indeed, it was reported by $\mathrm{G}$. Moran in Mulcahy \& Mulcahy (1987) that, in Monterey pine (Pinus radiata), 60 per cent of the genes expressed in the sporophyte are also expressed in the pollen. In some plant species, haploid pollen selection protocols have been developed to screen for destrable genes (Mascarenhas, 1990). Based on a variety of plant species, it has been suggested that the intensity of pollen selection is positively correlated with at least three separate factors: the distance competing pollen tubes must travel, the extent to which pollen grains outnumber available eggs, and the temporal pattern of pollen deposition (Mulcahy \& Mulcahy, 1987).

One further note on the reproductive biology of Picea species seems to underline the significance of the current test results. As pointed out by Fowler $\langle 1987\rangle$, the number of pollen grains that can actually be accommodated close to the micropyle in conifers is probably less than five. This number is significant in that only those pollen grains in this position could theoretically 'compete' or be selected. Therefore, larger numbers of males participating in a polymix pollen would first be subjected to a random process for entry to these positions. This would have a tendency to dampen differences in relative reproductive success. Thus, the use of six to seven males in this study's pollen mixes would theoretically reduce the probability of differences in success among males or gametes.

The present study was not designed to investigate mechanisms for selection, but only to test for evidence of selection in male contributions in black spruce. However, regardless of the means, the implications of this phenomenon can be discussed.

One effect of obvious consequence is bias in general combining ability estimates of black spruce where a polycross has been employed. However, as explained by Fowler (1987), this bias can be reduced to a negligible level by using many (i.e. 20 or more) males in the polymix. Perhaps the more significant implications of unequal male success in black spruce are in how we interpret and use the propagules that are derived from natural (i.e. natural stands or seed orchards) or controlled polycrosses. The effects on seed orchard seed could range from negligible to significant. To the extent that certain males may be more successful, despite management techniques aimed at controlling amount, timing, and direction of pollen flow, there may be a reduction in overall genetic diversity of the seed produced (relative to the diversity assumed, based on the number of reproductively mature males). However, it is also possible that selfs would be selected against, in which case there would be a reduction in the proportion of inbred seed produced.

In situations where polycrosses are used in con- 
trolled pollinations to produce seed for regeneration purposes, whether to be deployed as seedlings or stecklings, caution should be exercised in assuming relationships within these polycross families. They may well indeed be closer to full-sib than half-sib families. Some tree improvement programmes are already affected by policies relating to genetic diversity in regeneration propagules (e.g. OMNR, 1988b). Indeed, knowledge of the genetic quality of seed or other propagules used is requisite to responsible regeneration in forests or forest tree plantations.

\section{Acknowledgements}

We wish to recognize the technical expertise of $\mathrm{Mr}$ Peter Copis in producing the polycross seedlots. We gratefully acknowledge the insightful comments of Dr John Owens and the statistical review by $\mathrm{Dr}$ Bob Westfall. Anonymous reviewers made helpful comments that have improved the manuscript.

\section{References}

AASTVEITT, A. H. AND AASTVETT, K. 1990. Theory and application of open-pollination and polycross in forage grass breeding. Theor. Appl. Genet., 79, 618-624.

APSIT. V. I. NAKAMURA, R. R. AND WHEELER. N. C. 1989. Differential male reproductive success in Douglas fir. Theor. Appl. Genet., 77,681-684.

BOYLE, $\Upsilon$ J. J. B. 1986. Ten-year height growth of openpollinated black spruce families in Ontario. Can. For. Serv, petawawa Natl. For. Inst. Inf. Rep., PI-X-61.

CHELIAK, w. M. AND PITEL, J. A. 1984. Techniques for starch gel electrophoresis of enzymes from forest tree species. Can. For. Serv., Petawawa Natl. For. Inf. Rep. PI-X-42.

CopIS, P. L. 1990a. Pollination Techniques: I. Pollen collection. For, Can., Petawawa Natl. For. Inst. Tech. Rep., 4.

COPIS, P. L. 1990b. Pollination Techniques: II. Pollen extraction and storage. For. Can., Petawawa Natl. For. Inst. Tech. Rep., 5.

Copis, P. L. 1990c. Pollination Techniques: III. Flower development rating and pollen application. For. Can., Pelawawa Natl. For. Inst. Tech. Rep, 7.

ELLSTRAND, N. C. 1984. Multiple paternity within the fruits of wild radish, Raphanus sativus. Am. Nat., 123, 819-828.
FOWLER, D. P. 1987. In defense of the polycross. Can. J. For. Res, 17, 1624-1627.

HAMRJCK, J. L. AND SCHNABEL. A. 1985. Understanding the genetic structure of plant populations: some old problems and a new approach. In: Gregorius, H. R. (ed.), Population Genetics in Forestry, Springer-Verlag. Berlin Heidelberg, New York, pp. 50-70.

LINDGREN, D. AND YAZDANI, R. 1988. Paternal contributions following artificial pollination in Pinus sylvestris (L.). Scand. J. For. Res, 3, 299-304.

MASCAREnHAS, J. P. 1990. Gene activity during pollen development. Ann. Rev. Plant Phy. and Plant Mol. Biol., 41, $317-338$.

MORAN, G. F. AND GRIFFIN, A. R. 1985. Non-random contribution of pollen in polycrosses of Pints radiatus D. Don. Silvae Genet., 34, 117-121.

MUlCAHY, D. L. AND MULCAHY, G. B. 1975. The influence of gametophytic competition on sporophytic quality in Dianthus chinensis. Theor. Appl. Genet., 46, 277-280.

MULCAHY, D. L. AND MULCAHY, G. B. 1987. The effects of pollen competition. Am. Sci. 75, 44-50.

ONTARIO MiNISTRY OF NATURAL RESOURCES. 1988a. A Silvicultural Guide for the Spruce Working Group in Ontario. Science and Technology Series, vol. 4.

ONTARIO MINISTRY OF NATURAL RESOURCES. 1988b. Forest Resources Policy No. 120410.

OWENS, J. N. AND BLAKE, M. D. 1985. Forest tree seed production: A review of literature and recommendations for future research. Can. For. Serv. Natl. Inst. Inf. Rep. Pl-X53.

SCHOEN, D. J. AND CHELIAK. W. M. 1987. Genetics of the polycross: 2. Male fertility variation in Norway spruce, Picea abies (L.) Karst. Theor. Appl. Genet., 74, 554-559.

SCHOEN, D. J. AND STEWART, s. C. 1986. Variation in male reproductive investment and male reproductive success in white spruce. Evolution, 40, 1109-1120.

SOKAL, R. R. AND ROHLF, F. J. 1981. Biometry. 2nd edn. W, H. Freeman Company, New York.

SORENSEN, F. C. 1982. The roles of polyembryony and embryo viability in the genetic system of conifers. Evolution, 36, $725-733$.

STEPHENSON, A. G. AND BERTJN, R. I. 1983. Male competition, female choice and sexual selection in plants. In: Real, L. (ed.) Pollination Biology, Academic Press Inc., Orlando, Florida, USA, pp. 109-149.

WISELOGEL, A. E. AND VAN BUIJTENEN, J. P. 1988. Probability of equal mating in polymix pollinations of Loblolly pine (Pinus taeda L.). Silvae Genet., 37, 184-187. 